\title{
Differential Expression of an Inwardly Rectifying Chloride Conductance in Rat Brain Neurons: A Potential Mechanism for Cell-Specific Modulation of Postsynaptic Inhibition
}

\author{
R. L. Smith, ${ }^{1}$ G. H. Clayton, ${ }^{1}$ C. L. Wilcox, ${ }^{2}$ K. W. Escudero, ${ }^{2}$ and K. J. Staley ${ }^{1}$ \\ ${ }^{1}$ Department of Neurology and Pediatrics B182, University of Colorado Health Sciences Center, Denver, Colorado \\ 80262 and ${ }^{2}$ Department of Microbiology, Colorado State University, Ft. Collins, Colorado 80523
}

\begin{abstract}
A voltage-sensitive inwardly rectifying chloride $\left(\mathrm{Cl}^{-}\right)$conductance $\left(G_{\mathrm{CI}(\mathrm{V})}\right)$ is present in hippocampal pyramidal but not dentate gyrus neurons and has a significant role in modulation of neuronal inhibition by GABA. $G_{\mathrm{CI}(\mathrm{V})}$ has the same activation properties as the cloned and expressed $\mathrm{Cl}^{-}$channel CIC-2. In brain, $\mathrm{CIC}-2$ was detected selectively in neurons, and in hippocampus was detected in the same populations of neurons that demonstrate $G_{\mathrm{Cl}(\mathrm{V})}$. CIC-2 mRNA expression varied widely in different neuronal populations in brain but was greatest in pyramidal and other large neurons and least in interneurons. The observed differential expression of CIC-2 provides a potential molecular basis for the paradoxical excitation produced by GABA $_{A}$ receptor activation in selected neuronal populations.

[Key words: chloride channels, CIC-2, inhibition, gene expression, CNS, postsynaptic, disinhibition, GABA]
\end{abstract}

In a previous report, the functional properties of a hyperpolarization activated $\mathrm{Cl}$ conductance, designated $G_{\text {CI(V) }}$, was exannined in hippocanpal neurons (Staley, 1994). This conductance, which had been previously described by others in neurons and non-neuronal cells (Chesnoy-Marchais, 1983; Misgeld et al., 1986; Parker and Miledi, 1988), is shown to be inwardly rectifying with significant conductance only at membrane potentials more negative than the $\mathrm{Cl}$ transmembrane equilibrium potential $\left(E_{\mathrm{Cl}}\right)$ and to be of sufficient magnitude and duration to stabilize the relationship between $E_{\mathrm{Cl}}$ and resting membrane potential independent of electroneutral $\mathrm{Cl}^{-}$transport (Staley, 1994). Further, this conductance is present in pyramidal neurons but not neurons of the dentate gyrus (Staley, 1994). These properties suggest that $G_{\mathrm{CIV}}$ could represent a significant cell-specific mechanism for maintaining neuronal $\mathrm{Cl}$ homeostasis.

Neuronal $\mathrm{Cl}^{-}$homeostasis determines the direction and amplitude of $\mathrm{Cl}$ flux gated by $\mathrm{GABA}_{\mathrm{A}}$ and glycine receptors. Under most conditions $\mathrm{GABA}_{\mathrm{A}}$ and glycine are the principal chemical mediators of neuronal inhibition in the CNS (Misgeld et al., 1986); however, in some neurons $\mathrm{GABA}_{\mathrm{A}}$ receptor gated ion flux is paradoxically excitatory (Ben-Ari et al., 1989; Fizman et al.,

Received Sept. 26. 1994: revised Dec. 15, 1994: accepted Dec. 20, 1994.

This work was supported by an American Epilepsy Foundation grant and USPHS Grants CIDA NS15173 (K.J.S.) and AG10446 (C.L.W.). R.L.S is supported by UISPHS Grant CIDA NS $01741-01$; K.W.F., by NSF Award BIR9207439 .

Correspondence should be addressed to K. J. Staley, Department of Neurology and Pediatrics B 182. University of Colorado Health Sciences Center, 4200 East Ninth Avenue, Denver, CO 80262

Copyright (1) 1995 Society for Neuroscience 0270-6474/95/154057-11\$05.00/0
1990; Michelson and Wong, 1991; Xie and Smart, 1991, 1993; McIntire et al., 1993; Staley, 1994). For this condition to occur, $E_{\mathrm{Cl}}$ must be positive with respect to both the resting membrane potential and the action potential threshold (Staley, 1992; Staley et al., 1992); however, the resting membrane potential must be sufficiently negative that the voltage-sensitive cation channels responsible for generation of action potentials are not inactivated (Zhang and Jackson, 1993). The potential role of $G_{\mathrm{CHV}}$, in determining the effects of $\mathrm{GABA}_{\mathrm{A}}$ receptor-mediated $\mathrm{Cl}$ flux was shown in CAl pyramidal cells under conditions of neuronal $\mathrm{Cl}$ loading where $\mathrm{GABA}_{\mathrm{A}}$ receptor activation-triggered action potentials only when $G_{C(V)}$ was blocked. Therefore, under normal conditions $G_{\mathrm{ClV})}$ activation clamps $E_{\mathrm{Cl}}$ near the resting membrane potential, preventing the development of a driving force for depolarizing $\mathrm{Cl}$ efflux.

The $\mathrm{Cl}^{-}$conductance $G_{\mathrm{CIV})}$ that has been observed in hippocampal pyramidal neurons but not dentate gyrus neurons has properties that would be expected for the cloned and functionally expressed $\mathrm{Cl}^{-}$channel $\mathrm{ClC}-2$. A $\mathrm{ClC}-2$ cDNA, which was cloned from rat brain (Thiemann et al., 1992) and used to generate cRNA for expression in a Xenopus oocyte system (Grunder et al., 1992), displayed a voltage dependence similar to $G_{\mathrm{ClV} \text {. }}$. Both ClC-2 and $G_{\mathrm{Cl}(\mathrm{V})}$ slowly activate at hyperpolarized potentials, deactivate at depolarized potentials, and show no timedependent inactivation (Thiemann et al., 1992; Staley, 1994). ClC-2 mRNA is a relatively abundant rat brain $m R N \Lambda$, but is widely expressed in other tissues (Thiemann et al., 1992). Since CIC-2 mRNA is widely expressed in non-neuronal tissues and has properties that allow stabilization of cell volume, it has been proposed as a general mechanism for cellular homeostasis (Thiemann et al., 1992). ClC-2 is a member of the supergene family of voltage-gated, $\mathrm{Cl}$ channels that now includes $\mathrm{ClC}-0$ (Jentsch et al., 1990), ClC-1 (Steinmeyer et al., 1991), ClC-1K (Uchida et al., 1993), and ClC-3 (Kawashi et al., 1994). In addition to the property of voltage-dependent activation, members of this family of genes share a conserved transmembrane domain; however, extensive sequence divergence is present in the amino- and the carboxyl-terminal coding domains (Thiemann et al., 1992; Kawashi et al., 1994). Of the mammalian voltage-gated $\mathrm{Cl}$ channels, both $\mathrm{ClC}-2$ and $\mathrm{ClC}-3$ have been localized to brain (Thiemann et al., 1992; Kawashi et al., 1994). In this report, we have used in situ hybridization methods to determine that the pattern of distribution of $\mathrm{ClC}-2$ is consistent with the pattern of distribution of $G_{\mathrm{Cl}(\mathrm{V})}$ in hippocampus determined by electrophysiologic techniques. 

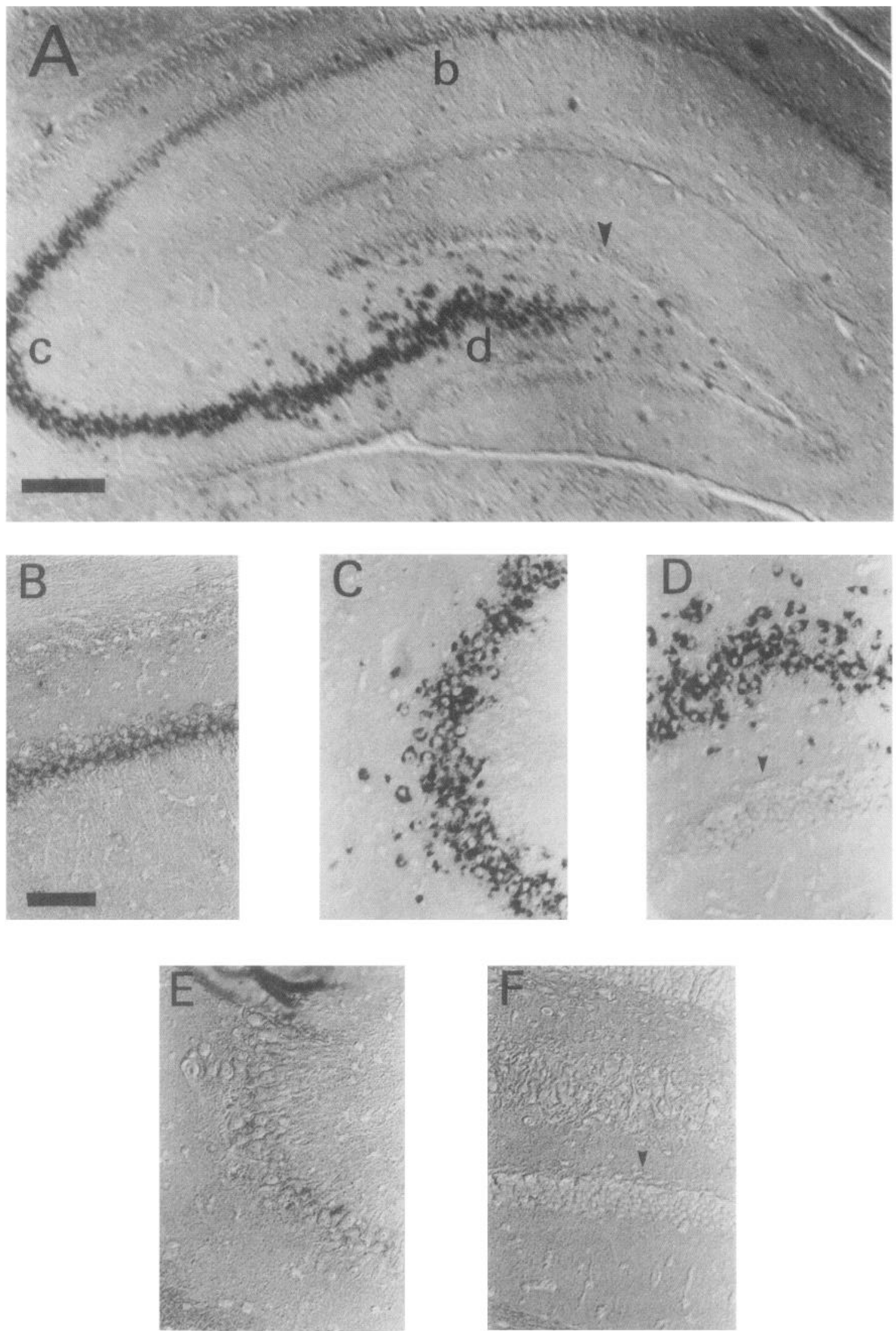

Figure 1. Detection of ClC-2 mRNA expression in hippocampus with a probe homologous to the 5 ' coding region. Photomicrographs of coronal sections through an adult rat brain hippocampus taken at the level of the medial habenular nucleus were examined for ClC-2 mRNA expression by in situ hybridization. Digoxigenin-labeled cRNA probes homologous to the 5' coding region (bp 63-277) were used. Hybridization was performed with an antisense probe in $A-D$ or a sense-strand control probe in $E$ and $F$. A, A low-power overview with the position of the high-power views 


\section{Materials and Methods}

C/C-2 probes. A cDNA clone derived from the $5^{\prime}$ coding region of CIC-2 was obtained using the reverse transcriptase polymerase chain reaction (RT-PCR) methods (Frohman, 1994) to amplify from polyAselected RNA prepared from $10^{8} \mathrm{PC}-12$ cells using a commercially available oligo-dT selection method (Microfast-track. Invitrogen). For amplification of the 5 coding region, a forward primer GGAAGGGATGGAGCCTCGAG 42-61 and reverse primer CCCTGGACACTAGGAACTTGT 277-256, referenced to the published CIC-2 sequence (Thiemann et al., 1992), allowed amplification of a PCR product that was initially cloned into the vector pCRII (Invitrogen, San Diego, CA). A subclone of this species was directionally cloned using an internal restriction site (Pst I; position 63) and a vector-derived EcoRI site ligated into the complementary Eco RI and Pst I sites of Bluescript KS (Stratagene, La Jolla, CA). A downstream coding region probe was obtained by RT-PCR as described above using a forward primer GTACCCATGTAGCCCTCAGC 1948-1969 and a reverse primer CCGGAGCTCCTTTAGGGTGAC 2703-2683. The identity of clones was confirmed by sequencing using an $\mathrm{Exo}^{-} \mathrm{Pfu}$ polymerase sequencing kit (Cyclist, Stratagene).

In situ hybridization. Whole rat brain was prepared by perfusion with molecular biology grade $\mathrm{HC}$ fixative (Amresco, Solon, OH) followed by immersion fixation overnight at $4^{\circ} \mathrm{C}$. The brain was then cut into 0.5 $\mathrm{cm}$ slices and immersion fixed for an additional $24 \mathrm{hr}$ in molecular biology grade $\mathrm{HC}$ fixative prior to dehydration and paraffin embedding by standard methods. Ten-micrometer sections were cut from paraffin blocks and mounted on pretreated slides (Superfrost plus, Fisher), and stored desiccated at $-20^{\circ} \mathrm{C}$ until use. Immediately prior to use, the tissue sections were cleared of paraffin with xylene washes and rehydrated.

In situ hybridization for detection of ClC-2 mRNA was performed at a final probe concentration of $2 \mathrm{mg} / \mathrm{ml}$ with either an antisense- or sense-strand-specific probe transcribed from a plasmid linearized with the appropriate restriction enzyme using either T3 or T7 DNA-dependent RNA polymerase in the presence of a labeling mixture containing digoxigenin-UTP and UTP at a ratio of 0.54 (Boehringer-Mannheim). The conditions of hybridization, RNAse treatment and washing were as previously described except that detergent was not included in the hybridization mixture (Smith et al., 1994). Immunodetection of digoxigenin was performed using alkaline phosphatase-conjugated antibodies (Anti-digoxigenin-AP, Fab fragments, Boehringer-Mannheim) at a dilution of 1:5000. Alkaline phosphatase-conjugated antibody binding was detected by incubation of slides at $4^{\circ} \mathrm{C}$ for $12 \mathrm{hr}$ in $100 \mathrm{~mm}$ Tris ( $\mathrm{pH}$ 9.5), $50 \mathrm{~mm} \mathrm{MgCl}, 100 \mathrm{mM} \mathrm{NaCl}, 1 \mathrm{~mm}$ Levamisole, and the chromogens nitroblue tetrazolium $(0.34 \mathrm{mg} / \mathrm{ml})$ and 5-bromo-4-chloro3 -indolyl phosphate $(0.175 \mathrm{mg} / \mathrm{ml})$, which produce a blue-black precipitate in cells with positive hybridization signal.

Representative sections were photographed with a Nikon Optiphot microscope equipped with Hoffman optics and automated film exposure using T-MAX 100 film. Views of cortex were acquired with an imaging system consisting of a COHU 4900 series CCD camera (Cohu, Inc.) fitted to a either a Nikon Optiphot microscope (Hoffman optics) or a $60 \mathrm{~mm}$ Micro-Nikkor macro lens. Digitized images were captured with a Macintosh 840AV computer equipped with a video framegrabber card (LG-3, Scion Corp.) and image analysis software (IMAGE 1.52, National Institutes of Health). Images were then processed using the software package PHOTOSHOP 2.5.1 (Adobe Systems, Inc.) and printed on a Kodak XL7700 photo printer.

Northern blot analysis. Standard methods as described (Sambrook et al., 1989) were used. PolyA-selected RNA was obtained from PC-12 cells using Microfast-track (Invitrogen, San Diego, CA) according to the manufacturers instructions.

Electrophysiology. Whole-cell recordings were obtained at $34^{\circ} \mathrm{C}$ in rat hippocampal slices as previously described (Staley et al., 1992; Staley, 1994). Where $\mathrm{ClC}-2$ and $\mathrm{ClC}-3$ activation was investigated, $\mathrm{Na}^{+}$, $\mathrm{K}^{+}$, and $\mathrm{Ca}^{2+}$ conductances, $\mathrm{HCO}_{3}^{-}-\mathrm{Cl}^{-}$exchange, and cation- $\mathrm{Cl}^{-} \mathrm{Co}-$ transport were blocked by using artificial cerebrospinal fluid (ACSF) composed of $109 \mathrm{~mm} \mathrm{NaCl}, 1.25 \mathrm{mM} \mathrm{NaH}_{2} \mathrm{PO}_{1}, 10 \mathrm{~mm}$ glucose, 20 $\mathrm{mm}$ tetraethylammonium chloride, $2.5 \mathrm{mM} \mathrm{CsCl}, 5 \mathrm{~mm}$ 4-aminopyridine, $4 \mathrm{~mm} \mathrm{MgCl}, 26 \mathrm{~mm} N$-(2-hydroxyethyl)piperazine- $N$ '-(2-ethanesulfonic acid) (HEPES), and $0.5 \mathrm{~mm}$ furosemide. The $\mathrm{pH}$ was adjusted to 7.4 with $\mathrm{NaOH}$, and the ACSF was saturated with $100 \% \mathrm{O}_{2}$. Electrode solutions included $120 \mathrm{mM} \mathrm{Cs}^{+}, 2 \mathrm{mM} \mathrm{MgCl}, 7 \mathrm{~mm} \mathrm{NaCl}$, $2 \mathrm{~mm}$ QX314, $10 \mathrm{~mm}$ IIEPES, $1 \mathrm{~mm}$ potassium ethylene glycol-bis $(\beta-$ aminoethyl ether)- $N, N, N^{\prime}, N^{\prime}$-tetraacetic acid (EGTA), $4 \mathrm{~mm}$ potassium adenosine $5^{\prime}$-triphosphate, and $0.3 \mathrm{~mm}$ sodium guanosine $5^{\prime}$-triphosphate; $\mathrm{pH}$ 7.2. When the resting membrane potential (RMP) and GA$\mathrm{BA}_{\mathrm{A}}$ synaptic excitation were measured, ACSF was composed of 126 $\mathrm{mM} \mathrm{NaCl}, 2.5 \mathrm{~mm} \mathrm{KCl}, 26 \mathrm{~mm}$ HEPES, $2 \mathrm{~mm} \mathrm{CaCl}, 2 \mathrm{~mm} \mathrm{MgCl} \mathrm{M}_{2}$, $1.25 \mathrm{mM} \mathrm{NaH}_{2} \mathrm{PO}_{4}, 10 \mathrm{~mm}$ glucose, and $0.5 \mathrm{~mm}$ furosemide; $\mathrm{pH} 7.4$; $\mathrm{K}^{+}$replaced $\mathrm{Cs}^{-}$in the electrode solution, and QX314 was not used. When the effects of synaptic $\mathrm{GABA}_{\mathrm{A}}$ receptor activation were investigated, glutamate receptor antagonists 6,7-dinitroquinoxaline-2,3-dione (DNQX; $10 \mu \mathrm{M})$ and kynurenate $(1 \mathrm{mM})$ and the $\mathrm{GABA}_{\mathrm{B}}$ antagonist CGP $35348(100 \mu \mathrm{M})$ were added to the ACSF. The stilbene derivative SITS was dissolved in DMSO (final concentration $<0.5 \%$ ) and applied by bath at a final concentration of $666 \mu \mathrm{M}$.

Activation of $\mathrm{ClC}-2$ and $\mathrm{ClC}-3 . \mathrm{ClC}-2$ currents were measured as the difference between the clamp current immediately after the capacitance transients had decayed (time average, $20-30 \mathrm{msec}$ after the voltage step) and the steady state current. $\mathrm{ClC}-3$ currents were measured using the time-averaged clamp current $20-30 \mathrm{msec}$ after the voltage step. Normalized, leak-subtracted currents were fit to a Boltzmann equation as described previously (Staley, 1994). Because of the overlapping activation potentials for $\mathrm{ClC}-3$ and $\mathrm{ClC}-3$, leak subtraction for $\mathrm{ClC}-2$ exploited the slow activation of this conductance and was based on the clamp current within $50 \mathrm{msec}$ of stepping to the test voltage. Leak subtraction for $\mathrm{ClC}-3$ utilized the ohmic region of the current-voltage relationship between -70 and $-30 \mathrm{mV}$, measured prior to the activation of $\mathrm{ClC}-2$.

Enzymes for modification of RNA and DNA were obtained from Promega (Madison, WI). Deep vent polymerase was from Ncw England Biolabs. All other routine reagents for molecular biology and electrophysiology were from Sigma (St. Louis, Mo.). CGP35348 was a gift of CIBA-GEIGY, (Basel, Switzerland), and QX314 was a gift from Astra (Westborough, MA).

\section{Results}

\section{Differential expression of ClC-2 mRNA in hippocampal neurons}

ClC-2 cDNA sequence exhibits significant divergence from other cloned voltage-gated $\mathrm{Cl}^{-}$channels $(\mathrm{ClC}-0, \mathrm{ClC}-1, \mathrm{ClC}-1 \mathrm{~K}$ and $\mathrm{ClC}-3$ ) at the amino-terminal coding domain (Thiemann et al., 1992; Kawashi et al., 1994). Based on the published sequence of $\mathrm{ClC}-2$, primers (20-mers) were selected to amplify a 235 bp segment from the amino-terminal coding domain using PC-12 RNA that had been reverse transcribed. The identity of the product was confirmed as described in Materials and Methods by DNA sequence and the ability of labeled probe prepared from this clone to detect a $3.3 \mathrm{~kb}$ species on Northern blots of polyA-selected RNA from PC- 12 cells as predicted by published results (Thiemann et al., 1992).

We have previously shown that an inwardly rectifying $\mathrm{Cl}^{-}$ conductance with voltage dependence similar to $\mathrm{ClC}-2$ was expressed in hippocampal pyramidal neurons hut not neurons of the dentate gyrus (Staley, 1994). To determine if the expression of CIC-2 mRNA correlated with this conductance, in situ hybridization was performed using a 235 bp cRNA probe from the $5^{\prime}$ coding region. As shown in Figure 1, an in situ hybridization

in $b-l)$ indicated $(b-d) . B$, The CA1 region. $C$, The CA3 region. $D$, The CA4 and dentate gyrus. Hybridization with a sense-strand control probe is shown in $E$ for the CA3 region and in $F$ for CA4 and dentate gyrus. The position of the horizontally elongated interneurons found adjacent to the granule cells is indicated by an arrowhead in $D$ and $F$. Hybridization signal (antisense) was detected in the cytoplasm of pyramidal cells but not in the dentate gyrus or in most cell profiles of the molecular layer or subhilar region $(A-D)$. No cytoplasmic signal was detected with the sensestrand control probe $(E$ and $F)$. Scale bars: $A, 250 \mu \mathrm{m} ; B, 100 \mu \mathrm{m}$ for $B-F$. 
A
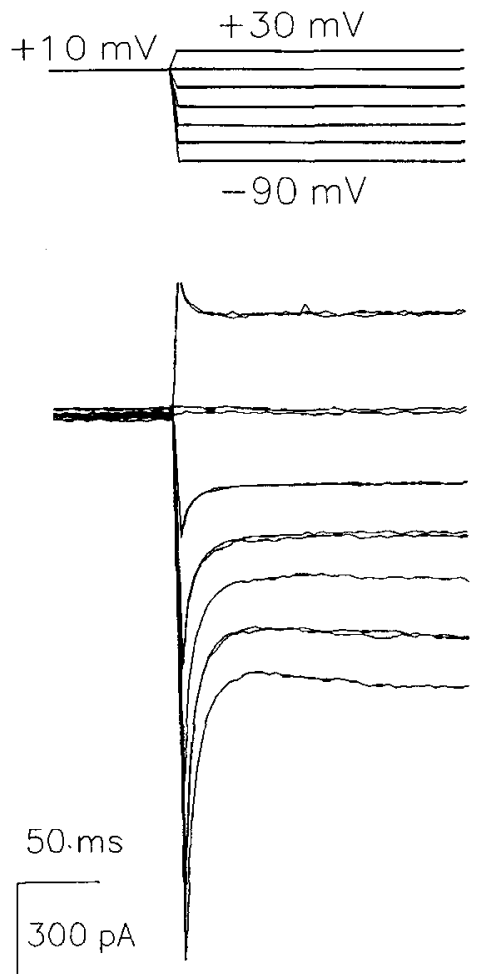

B
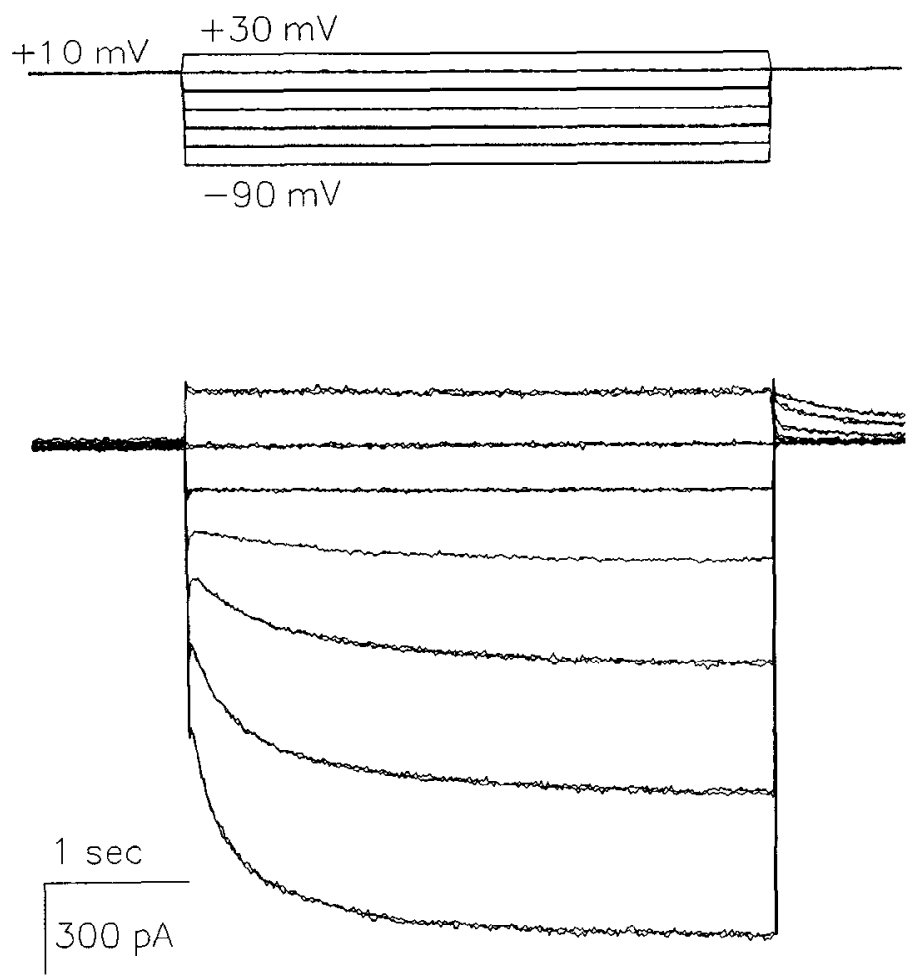

D

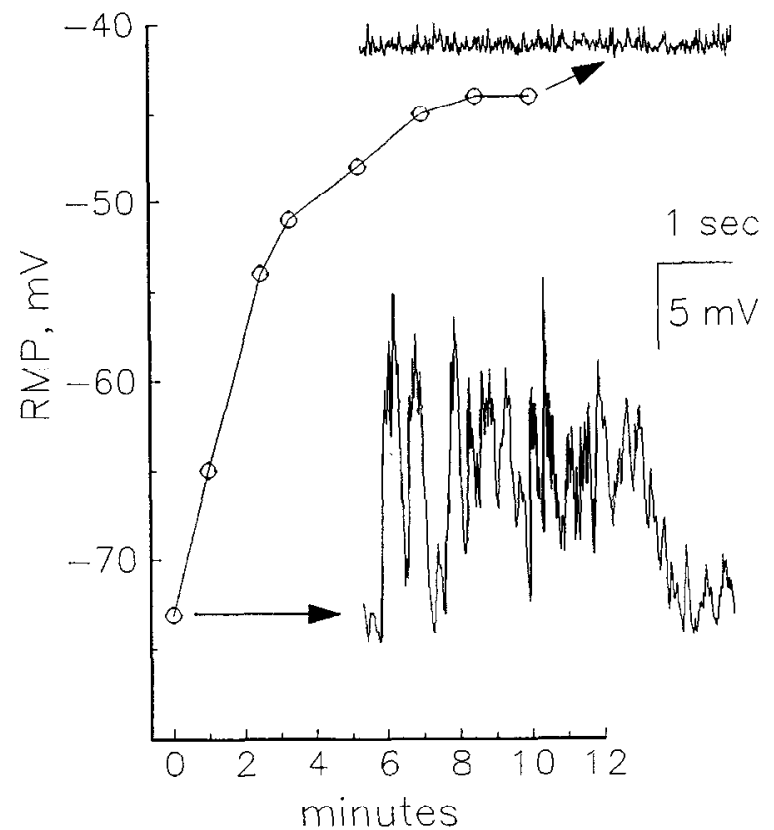

Figure 2. Activation of $\mathrm{ClC}-2$ and $\mathrm{ClC}-3$ in hippocampal pyramidal neurons. A, Voltage-clamp recording using a $125 \mathrm{~mm} \mathrm{Cl}^{-}$electrode solution in a $\mathrm{CA} 3$ pyramidal neuron in which cationic conductances were blocked. Initial clamp currents induced by voltage steps from a holding potential 
signal was obtained in hippocampal neurons using a cRNA antisense probe (Fig. $1 A-D$ ), but not a sense-strand control probe (Fig. 1E,F). An intense in situ hybridization signal was observed in pyramidal cells, which was generally greater in CA3 and CA4 than in CAl (Fig. $1 B, C$ ). In contrast, essentially no signal was detected in the dentate gyrus with the exception of occasional scattered cells (Fig. 1A,D). GABAergic neurons that are involved in local inhibitory circuits are present throughout the molecular layer surrounding the hippocampus and immediately proximal to the dentate gyrus in the subhilar regions (Ribak et al., 1978; Seress and Ribak, 1983; Michelson and Wong, 1991). ClC-2 mRNA expression was not detected in most cell profiles of the molecular cell layer except for very rare cells. Many cell profiles that have morphologic features of neurons were clearly identified in the molecular layer (Fig. 1A,B). Similarly, cells with the horizontally elongated morphology of interneurons were seen proximal to the dentate gyrus that did not express CIC-2 mRNA (Fig. 1D). Given the diversity of interneuron classes that have been identified within the hippocampus (Buhl et al., 1994), the presence of occasional interneurons expressing $\mathrm{ClC}-2$ mRNA is not surprising. However, these results indicate that a large portion of interneurons did not express ClC-2 mRNA at detectable levels. In the control sections using the sense-strand probe a faint brown extracellular signal was sometimes been seen in the area of CA3 (Fig. $1 E$ ). This faint signal was easily distinguishable from specific staining pattern and is the only region of brain that has shown even faint nonspecific signal with the methods used. in situ hybridizations were also performed using a probe homologous to the region of $\mathrm{ClC}-2$ from 1948 to 2703 and identical results were obtained (data not shown). These results indicate that in the hippocampus, expression of $\mathrm{ClC}-2$ mRNA was largely restricted to pyramidal neurons.

\section{Electrical expression of an inwardly rectifying $\mathrm{Cl}^{-}$ conductance is closely correlated with in situ hybridization signal for $\mathrm{ClC}-2 \mathrm{mRNA}$}

The previous electrophysiologic study focused on $G_{\mathrm{CI}(\mathrm{V})}$ in the region of CAl and the dentate gyrus (Staley, 1994). The in situ hybridization results indicate that this inwardly rectifying $\mathrm{Cl}$ conductance should be present throughout the pyramidal layer. As shown in Figure 2, an inwardly rectifying $\mathrm{Cl}^{-}$conductance with the activation characteristics of $G_{\mathrm{Cl} V \mathrm{~V}}$, and $\mathrm{ClC}-2$ was present in all pyramidal cell regions of the hippocampus. Sixteen of 16 pyramidal cells in area CA3 and CA4 demonstrated the $G_{\mathrm{Cl}(\mathrm{V})} /$ ClC-2 conductance. $\mathrm{ClC}-3$ is a $\mathrm{Cl}^{-}$channel that is also expressed in the brain neurons, and is heavily expressed in hippocampus (Kawashi el al., 1994). Figure $2 A-C$ illustrates that ClC-3 can be functionally differentiated from $\mathrm{ClC}-2$ based on activation at depolarized versus hyperpolarized potentials, the kinetics of activation, and sensitivity to the stilbene derivative SITS. Since
ClC-2 activates at potentials negative to the $\mathrm{Cl}^{-}$reversal potential, activation of $\mathrm{ClC}-2$ can also be demonstrated by depolarization of the RMP in pyramidal cells that are loaded with $\mathrm{Cl}^{-}$ via the recording electrode (Fig. $2 D$ ). When the $\mathrm{Cl}$ reversal potential is set near $0 \mathrm{mV}$ using a $125 \mathrm{mM} \mathrm{Cl}^{-}$electrode solution, activation of $\mathrm{ClC}-2$ results in a gradual depolarization of the RMP due to uncompensated loss of $\mathrm{Cl}^{-*}$. Activation of $\mathrm{ClC}-2$ drives the RMP toward the $\mathrm{Cl}^{-}$reversal potential, demonstrated by the reduction in amplitude of the spontaneous synaptic potentials due to $\mathrm{Cl}^{-}$flux through the $\mathrm{GABA}_{\mathrm{A}}$ receptor-linked ionophore (Fig. 2D)

\section{ClC-2 $m R N A$ is differentially expressed in rat brain and spinal cord}

Analysis of the distribution of ClC-2 mRNA within the CNS provides for an understanding of one of the cellular mechanisms responsible for neuronal $\mathrm{CI}^{-}$homeostasis in the CNS. The distribution of ClC-2 mRNA expression detected using the 5 '-specific probe is summarized in Table 1 and illustrated for specific regions of the brain as described below in Figures 3-5.

Cerebellum. ClC-2 mRNA expression in cerebellum, as in hippocampus, provides another example of differential expression of ClC-2 in different neuronal populations. In cerebellum, ClC-2 mRNA hybridization was clearly greatest in the Purkinje cells but, in contrast to hippocampus, was expressed in most cells of the molecular layer at moderate levels (Fig. $3 A$ ). Signal was not detected in the granular cell layer with the exception of scattered cells. Moderate signal was also present in the deep nuclei of cerebellum (Table 1). As shown in Figure $3 B$, no signal was seen with the sense-strand control probe. The pattern of expression within the cerebellum was thus consistent with hippocampus, where the largest class of neurons demonstrated the highest level of expression; however, the expression of CIC-2 mRNA was much greater in cerebellar molecular layer neurons than that detected in the hippocampal molecular layer.

Spinal cord. Motor neurons had the most conspicuous signal (Fig. 3C), while sections hybridized with a sense-strand control probe did not demonstrate signal (Fig. 3D). ClC-2 mRNA hybridization signal was also detected within central and lateral cervical nuclei and in rare neurons of the posterior horn (Table 1). As in other regions, hybridization was never observed in association with white matter tracks.

Cerebral cortex. ClC-2 mRNA was widely expressed in cortex but varied depending on the region of cortex examined. The coronal image and the corresponding inset in Figure 4 illustrated this variation in expression. In cingulate cortex, $\mathrm{ClC}-2$ mRNA was minimally expressed. In the region of frontoparietal motor cortex expression was largely restricted to layer $\mathrm{V}$ and as shown in the inset was minimally expressed in layer IV. In more lateral regions, corresponding to somatosensory cortex, expression was

\section{$\leftarrow$}

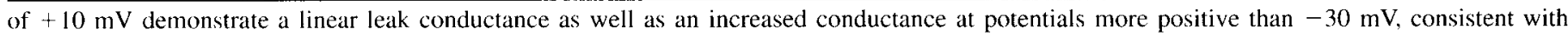

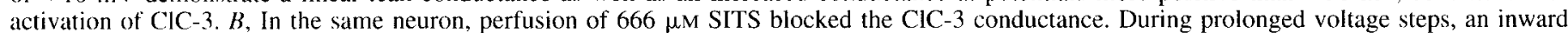

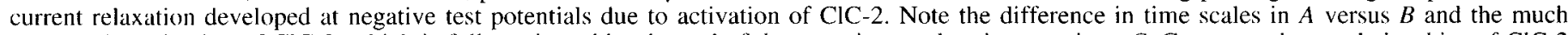

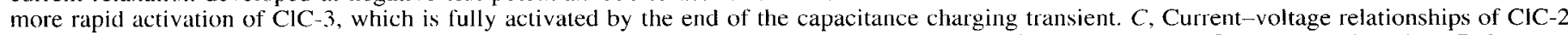

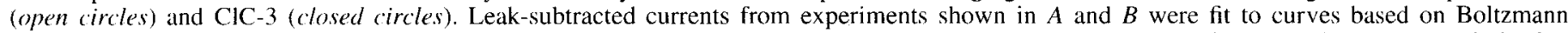

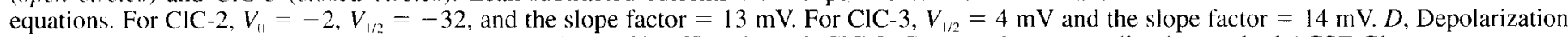

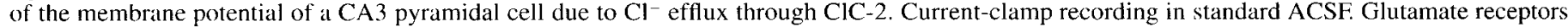

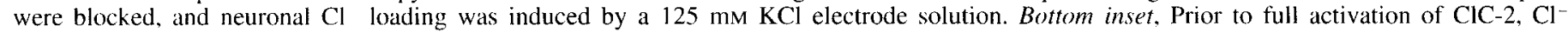

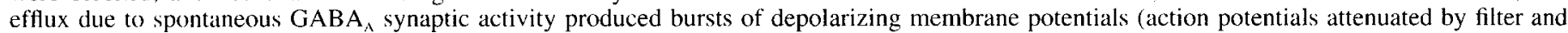

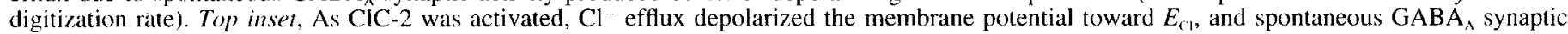
activity no longer depolarized the neuron nor triggered action potentials. 

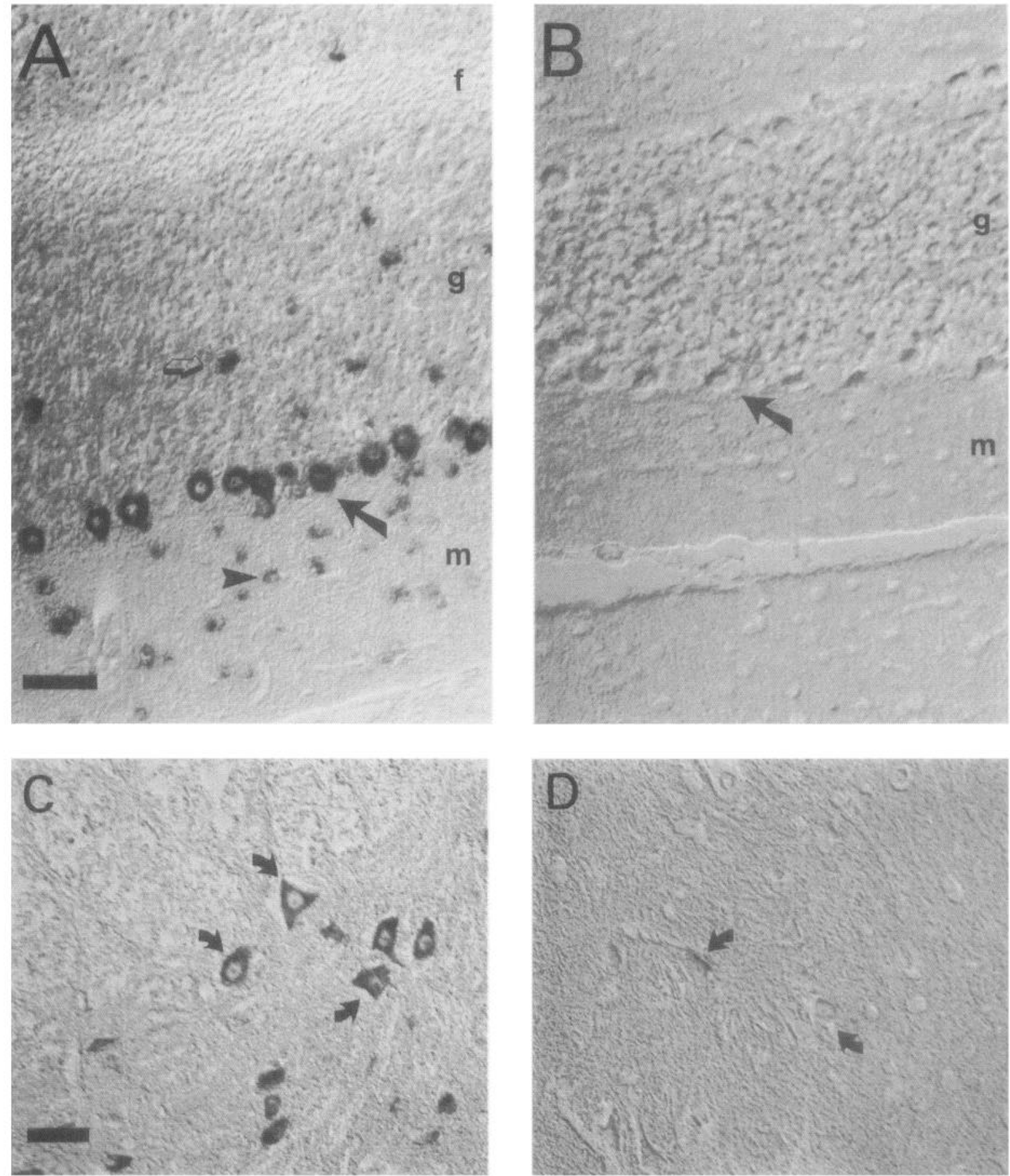

Figure 3. ClC-2 mRNA expression in cerebellum and spinal cord is restricted to specific cell types. Photomicrographs of coronal sections of cerebellum and transverse sections of cervical spinal cord were examined for ClC-2 expression using the $5^{\prime}$ coding region probe. A, Cerebellum. Strong hybridization signal (antisense) was found primarily within the large Purkinje cells (closed arrow), with occasional labeling of a subpopulation of cells within the granular cell layer $(\mathrm{g})$ (open arrow), frequent moderate staining of cell profiles within the molecular cell layer $(\mathrm{m})(\mathrm{arrowhead})$, but no signal in the fiber layer $(f) . B$. Cerebellum control. Section adjacent to $A$ hybridized with the sense-strand probe had no detectable signal, The position of Purkinje cells between the granular $(\mathrm{g})$ and molecular $(\mathrm{m})$ layers is indicated by an arrow. $C$, Anterior horn of spinal cord. Signal was detected with the antisense probe within anterior horn cells (arrows; see Results). D, Spinal cord control. Sections hybridized with sense-strand probes show profiles of large motor neurons that contain no signal (arrows). Scale bars, $50 \mu \mathrm{m}(A$ also for $B, C$ also for $D$ ).

widespread but again reduced in layer IV compared to layer $\mathrm{V}$. Ventral to the rhinal fissure, the pyramidal neurons in layer II of primary olfactory cortex expressed the highest levels of CIC-2 mRNA. This pattern of more extensive cortical expression in lateral regions was also observed in coronal sections either an- terior or posterior to the section shown. As for other regions of brain, no signal was obtained when a sense-strand control probe was used to perform in situ hybridizations (data not shown).

Diencephalon. The abundance of $\mathrm{ClC}-2$ mRNA expression varied widely in different regions of the brain. In deep structures 


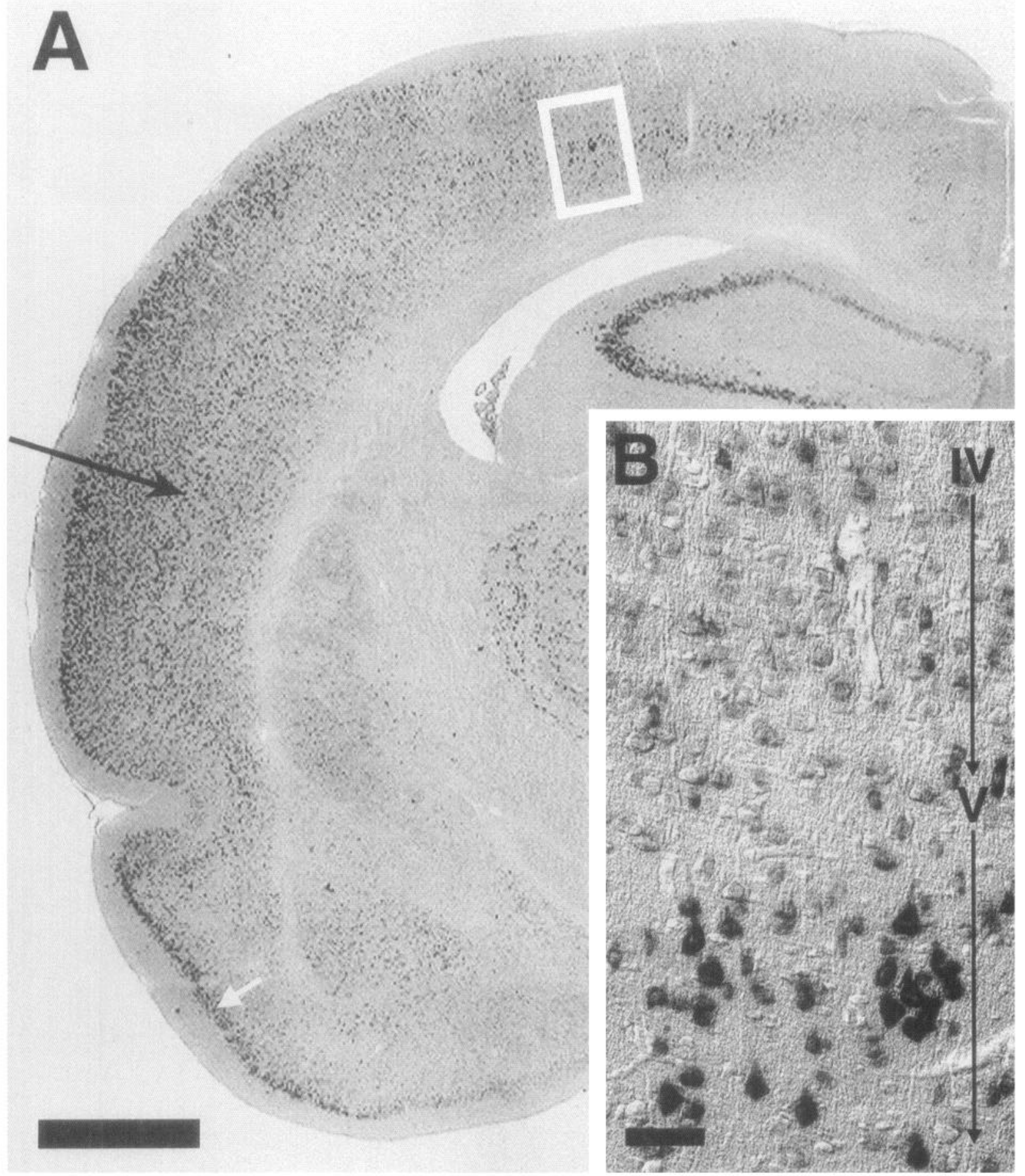

Figure 4. $\mathrm{ClC}-2$ mRNA is differentially expressed in cerebral cortex. Representative hemisection (coronal, $10 \mu \mathrm{m})$ through the anterior diencephalon shows the cortical distribution of ClC-2 hybridization signal. A, ClC-2 hybridization signal was least intense from the region of cingulate cortex to frontoparietal primary motor cortex (boxed area) where signal was most intense within layer V. Within the frontoparietal somatosensory cortex hybridization signal was more widespread but remained greatest in layer V (black arrow). Ventral to the rhinal fissure the primary olfactory cortex consists of three layers and hybridization signal was concentrated within the pyramidal cells of layer II (white arrow). B, Magnified view of boxed area in $A$. The cells within layer $\mathrm{V}$ are more intensely labeled than those in layer IV above. No staining was observed in sections stained with the sense-strand control probe (data not shown). Scale bars: $A, 1 \mathrm{~mm} ; B, 50 \mu \mathrm{m}$.

of forebrain signal was present in diagonal band and medial septal nuclei but absent in the lateral septal nucleus (Table 1). Portions of the substantia nigra (pars compacta) and ventral tegmental nuclei expressed large amounts of ClC-2 mRNA (Fig. $5 A$ ). Some areas such as caudoputamen, accumbens, and globus pallidus were devoid of signal with the exception of rare cells (Fig. 5B). Moderate expression was seen throughout the thalamus with the exception of intense signal in the reticulothalamic (Fig. $5 C$ ) and the anterodorsal nuclei (Fig. 5D). In epithalamus, the medial habenular nucleus was heavily stained (Fig. $5 G$ ). In 

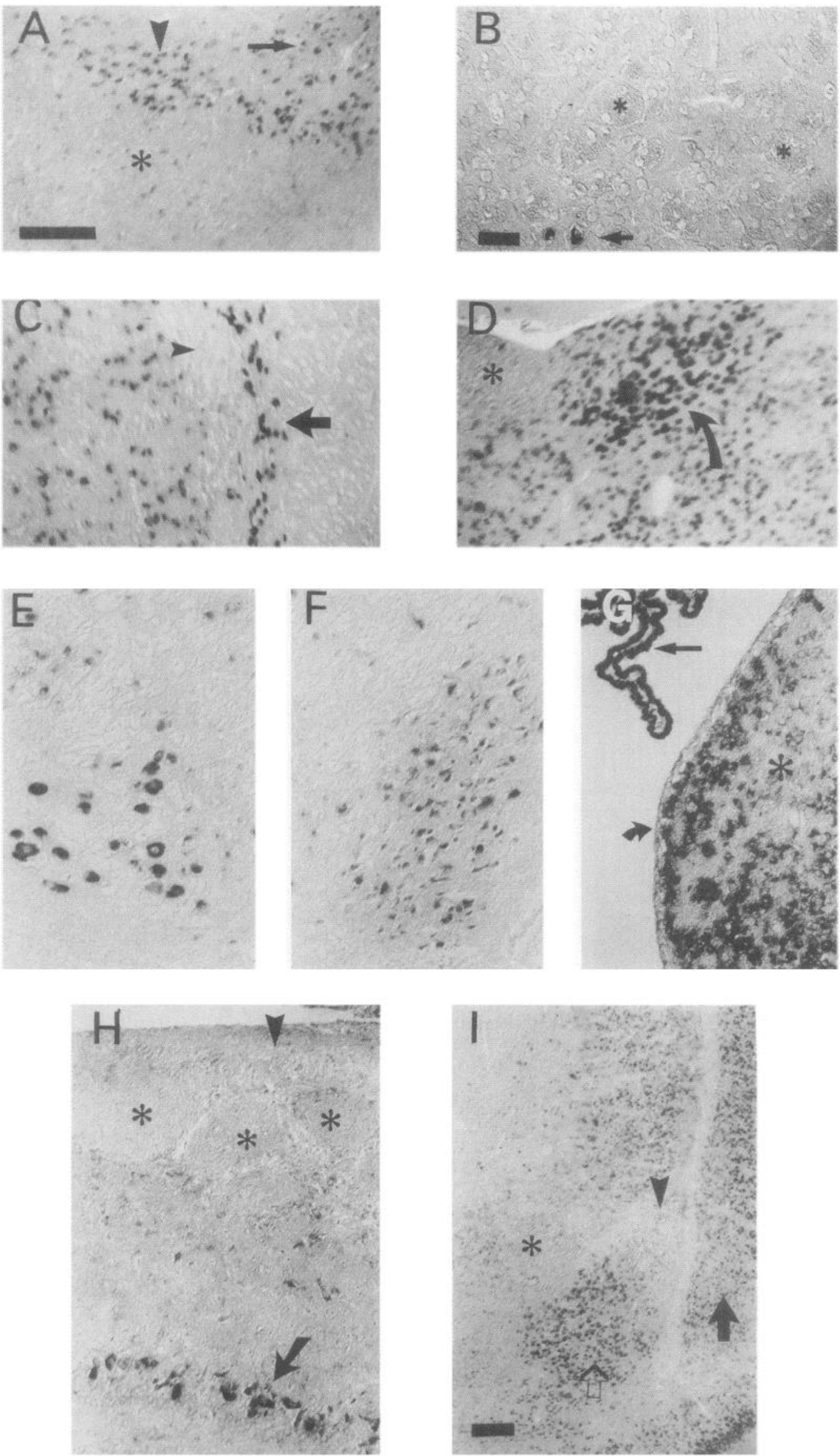
the amygdala, marked variation was observed between individual nuclei with the basolateral amygdaloid nucleus demonstrating intense signal while the lateral and medial amygdaloid nuclei contained little signal (Fig. $5 I$ ).

Olfactory. Expression of $\mathrm{ClC}-2$ mRNA was restricted in the olfactory bulb to the mitral cell layer (Fig. $5 H$ ). As noted in other brain regions, CIC-2 mRNA hybridization signal was lacking in the granular cell layer or in the granular cells that lie in clusters in close proximity to the mitral cells.

Brainstem. In midbrain, minimal staining was detected in the region of the colliculi (Table 1 ). In contrast, the mesencephalic trigeminal nucleus and locus coeruleus (Fig. $5 E, F$, respectively) demonstrated intense staining. Staining was also seen in the auditory nuclei, the cuneate/gracile nuclei and in motor nuclei of cranial nerves (Table 1).

Non-neuronal structures. Throughout brain and spinal cord, CIC-2 mRNA expression was confined to regions containing neurons and was not found in white matter, blood vessels or meninges. In most areas, the methods used allowed signal to be localized to the somas of specific neurons. One exception to this pattern of neuron-specific expression was found in the epithelial cell layer of choroid plexus, where significant $\mathrm{ClC}-2$ hybridization signal was present (Fig. $5 G$ ). In contrast, ClC-2 mRNA was not expressed at detectable levels in ependymal cells. This suggests that $\mathrm{ClC}-2$ may be involved in $\mathrm{Cl}^{-}$transport in the choroid plexus.

\section{Discussion}

The similarity between the activation properties of the cloned $\mathrm{Cl}^{-}$channel $\mathrm{ClC}-2$ and the neuronal $\mathrm{Cl}^{-}$conductance $G_{\mathrm{CIr} \text { ) }}$ (Thiemann et al., 1992; Staley, 1994) and the colocalization of $G_{\mathrm{CIV})}$ to the same neuronal populations that express $\mathrm{ClC}-2$ mRNA, strongly suggest that $\mathrm{ClC}-2$ mediates $\mathrm{G}_{\mathrm{Cl} \text { V) }} \cdot \mathrm{ClC}-2$ is unique among the channels described to date because of inwardly rectifying characteristics and the osmotic modulation of activation properties, which suggests a fundamental role in cell volume control (Thiemann et al., 1992). However, in the CNS, ClC-2 may have functions in addition to the control of cell volume. This is supported by the pattern of expression of $\mathrm{ClC}-2$ mRNA in the CNS, where expression was limited to specific populations of neurons, undetectable in glia, and marked in the specialized epithelium of choroid plexus. This pattern is in contrast to the ubiquitous pattern that would be expected for a conductance necessary for regulation of cell volume alone.
Neuronal $\mathrm{ClC}-2$ and $\mathrm{ClC}-3$ and regulation of $\mathrm{Cl}^{-}$conductance

Conductances with properties predicted for the $\mathrm{ClC}-2$ and $\mathrm{ClC}-3$ $\mathrm{Cl}^{-}$channels can be readily identified in neurons. Both show no significant time-dependent inactivation, and the amplitudes of the whole-cell conductances are approximately the same (Fig. $2 C$ ). The channels were distinguished by their activation properties, since $\mathrm{ClC}-2$ was activated at potentials negative to the $\mathrm{Cl}^{-}$transmembrane equilibrium potential, while ClC-3 was activated at potentials above $-30 \mathrm{mV}$, and we have no evidence that the activation of $\mathrm{ClC}-3$ was affected by the $\mathrm{Cl}^{-}$equilibriun potential. The block of $\mathrm{ClC}-3$ by stilbene derivatives further distinguishes $\mathrm{ClC}-3$ from $\mathrm{ClC}-2$, which is unaffected by extracellular stilbenes (Fig. 2B; Chesnoy-Marchais, 1983).

ClC-2 and ClC-3 differ further in their pattern of mRNA expression. The restricted pattern of expression of $\mathrm{ClC}-2$ in brain described in this report was in contrast to a more ubiquitous pattern seen with the recently cloned CIC-3 (Kawashi et al., 1994). ClC-3 is a relatively abundant $\mathrm{Cl}^{-}$channel in brain with outwardly rectifying properties which, like $\mathrm{ClC} 2$, is expressed in neurons but not glia. In contrast to $\mathrm{ClC}-2$, the pattern of $\mathrm{ClC}-3$ expression in neurons is more homogeneous, with signal in both dentate and pyramidal cells of hippocampus, and widespread expression in both olfactory bulb and cerebral cortex (Kawashi et al., 1994).

In patch-clamp studies $\mathrm{Cl}^{-}$channels are rarely observed in cell-attached mode but are readily seen in detached patches (Blatz, 1991). In whole-cell studies, the amplitude of the $\mathrm{Cl}^{-}$ conductance increases with recording time. These results suggest that $\mathrm{Cl}^{-}$channels are subject to intracellular regulation. In Xenopus oocytes $\mathrm{ClC}-3$ was shown to be inhibited by activators of protein kinase C (PKC) (Kawashi et al., 1994). In hippocampal slice preparations, $G_{\mathrm{Cl}(\mathrm{V})}$ also demonstrates regulation by modulators of second-messenger systems; activators of PKC block $G_{\mathrm{Cl}(\mathrm{V})}$ (Madison et al., 1986) while activation of PKA increases the conductance (Staley, 1994). Therefore, although $\mathrm{ClC}-3$ and ClC-2 have different patterns of distribution, both are subject to regulation by second-messenger systems, suggesting that activation of these channels may be conditional. The specific mechanisms of regulation are unknown for both $\mathrm{ClC}-2$ and $\mathrm{ClC}-3$. It is clear in the case of $\mathrm{ClC}-2$ that the regulatory function resides in the amino-terminal domain, and this function can be maintained even when this domain is placed in a carboxyl-terminal position (Grunder et al., 1992). In ClC-3, a consensus phosphorylation site for $\mathrm{PKC}$ is present (Kawashi et al., 1994) but

$\leftarrow$

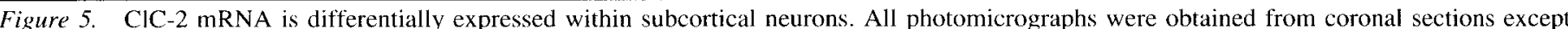

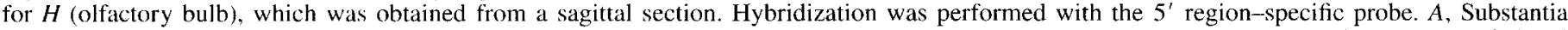

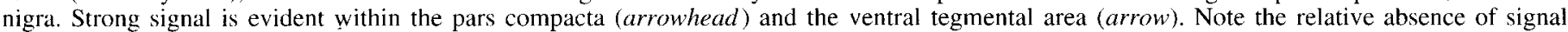

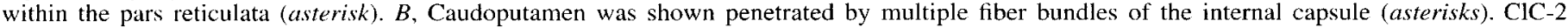

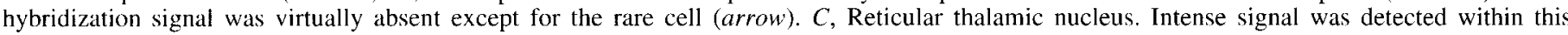

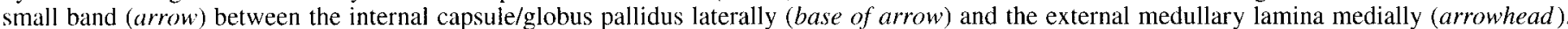

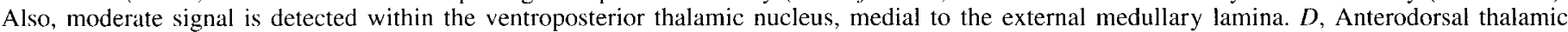

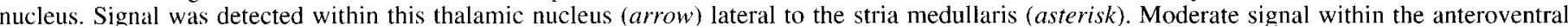

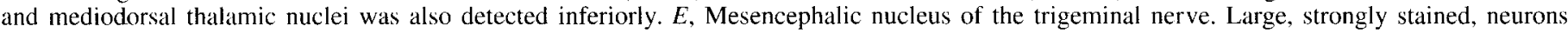

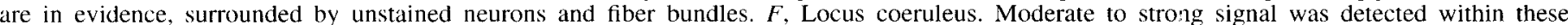

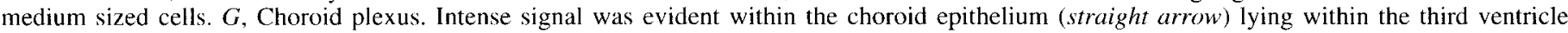

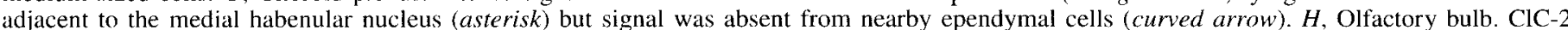

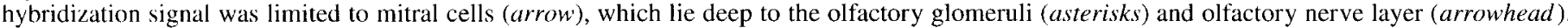

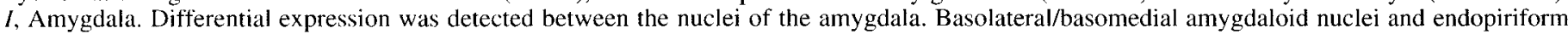

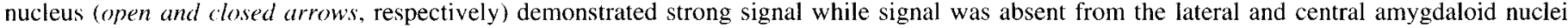

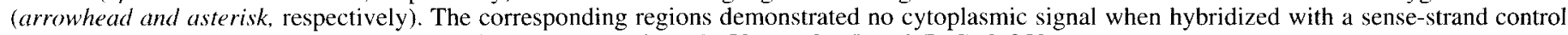
probe (not shown). Scale bars: $A, 200 \mathrm{~mm}$ for $A, C, D$, and $H ; B, 50 \mathrm{~mm}$ for $B$ and $E-G ; I, 250 \mu \mathrm{m}$. 


\section{Table 1. Distribution of C1C-2 mRNA expression within the rat brain and spinal cord}

CNS region Signal

Olfactory system

Accessory olfactory bulb

Mitral cells

Olfactory bulb

External plexiform layer

Glomerular layer

Internal granular layer

Internal plexiform layer

Mitral cell layer

Olfactory nerve layer

Olfactory tubercle

Primary olfactory cortex

Cortex (see Results)

Basal ganglia

Accumbens nucleus

Caudoputamen

Entopeduncular neucleus

Globus palidus

Substantia nigra

Pars compacta

Pars reticulata

Ventral tegmental area

Hippocampus

CAI

CA3

CA4

Dentate gyrus

Entorhinal cortex

Subiculum

Septum

Diagonal band

Lateral septal nucleus

Medial septal nucleus

Amygdala

Basolateral complex

Central nucleus

Lateral

Medial

Endopiriform nucleus

Lateral nucleus

Medial nucleus

Anterodorsal

Anteroventral

Epithalamus

Habenula

Lateral

Medial

Stria medularis

Thalamus

Anterodorsal nucleus

Laterodorsal nucleus

Reticulothalamic nucleus

Zona incerta

VL

VM

VPL

VPM

$+$

$+++$

$-$

$+++$

$+$

$+++$

$-$

$++$

$++$

$++$

$++$
Table 1. Continued

CNS region

Signal

Hypothalamus

Arcuate nucleus

Dorsal area

Dorsomedial area

Lateral area

Periventricular area

Supraoptic nucleus

Ventromedial area

Cerebellum

Cortex

Molecular layer

Purkinje layer

Granular layer

Deep nuclei

Midbrain/brainstem

Auditory nculei

Facial nucleus

Gracile/cuneate nuclei

Inferior/superior colliculi

Locus coeruleus

Mesencephalic trigeminal nucleus

$++$

$+$

$+$

$-$

$++$

+ to ++

Pontine nuclei

Red nucleus

Vestibular nuclei

Spinal cord

Central cervical nucleus

Interneurons (scattered)

Lateral cervical/spinal nucleus

Motor neurons $(\alpha / \gamma)$

Sensory layers 1-6

$+++$

$-a$

$++$

$++$

$+++$

$++$

$-$

$+++$

$+++$

$+++$

$-$

$++$

$+++$

$+$

$+++$

$+++$

$-"$

White matter

Non-Neuronal elements

White matter

Choroid epithelium

Ependyma

Meninges

The intensity of hybridization signal in specific CNS regions was scored on an arbitrary scale from no detectable signal, which corresponded to the intensity detected on control sections $(-)$, to intense labeling $(+++)$.

"Areas generally not stained but containing the occasional labeled cell.

such sequences are not found in ClC-2 (Thiemann et al., 1992). However, direct regulation by phosphorylation has not been demonstrated for either $\mathrm{ClC}-2$ or $\mathrm{ClC}-3$, and mechanisms of regulation remain an important area of investigation.

\section{Significance of ClC-2 mRNA distribution}

The roles of the voltage-sensitive $\mathrm{Cl}^{-}$channels and ion-specific inward rectifiers in neuronal physiology are still being determined. One function of inwardly rectifying $\mathrm{Cl}$ conductances is stabilization of the relationship between the membrane potential and the $\mathrm{Cl}^{-}$equilibrium potential. This prevents paradoxical excitation via GABAergic inhibitory circuits under conditions of $\mathrm{Cl}^{-}$loading such as occur during high-frequency synaptic activation (Wong and Watkins, 1982; Thompson and Gahwiler, 1989; Staley, 1994). The finding that ClC-2 mRNA is not expressed in the morphologically identified interneurons of the hippocampal hilar region nor in most of the neuronal profiles of the 
molecular layer thus suggests a potential mechanism for the paradoxical excitation of interneurons by activation of $\mathrm{GABA}_{\mathrm{A}}$ receptors (Michelson and Wong, 1991). The absence of ClC-2 permits $\mathrm{Cl}$ accumulation in the interneurons to the point that $\mathrm{Cl}^{-}$flux through the $\mathrm{GABA}_{\mathrm{A}}$ receptor-associated ionophore is outward, and depolarizes the neuron to the activation voltage of the sodium conductances which underlie the action potential (i.e., Fig. $2 D$, bottom inset). Therefore, the differential expression of $\mathrm{ClC}-2$ is an important factor in understanding the effects of $\mathrm{GABA}_{\mathrm{A}}$ activation.

The most striking feature of the distribution of $\mathrm{ClC}^{-}-2$ mRNA was the high level of expression in the largest classes of neurons. As noted, there were several clcar exceptions to this pattern. However, the correlation between $\mathrm{ClC}-2$ expression and neuronal size raises the possibility that both $\mathrm{CIC}-2$ and somatic volume are mechanisms of intracellular $\mathrm{Cl}^{-}$homeostasis. High-frequency $\mathrm{GABA}_{\mathrm{A}}$ receptor activation leads to intracellular $\mathrm{Cl}^{-}$accumulation (Wong and Watkins, 1982; Thompson and Gahwiler, 1989) and the increase in neuronal $\mathrm{Cl}^{-}$concentration is directly related to the intracellular volume (Qian and Sejnuwski, 1990). Therefore, the large somatic volume provides one mechanism to minimize the fluctuation in $\mathrm{Cl}^{-}$concentration. $\mathrm{ClC}-2$ expression is an additional mechanism that prevents shifts in the transmembrane $\mathrm{Cl}^{-}$gradient such that the $\mathrm{Cl}^{-}$reversal potential is positive with respect to the steady-state membrane potential. Such mechanisms might be particularly suited to neurons in which $\mathrm{GABA}_{\mathrm{A}}$ receptor activation occurs in high-frequency bursts, which appears to occur in the hippocampal pyramidal cells (Buzsaki et al., 1992). Both of these mechanisms are passive, so that this hypothesis suggests that these neurons would also express high levels of active Cl transport proteins such as the cation- $\mathrm{Cl}^{-}$ cotransporter, as occurs in the choroid plexus (Javaheri, 1991).

The pattern of $\mathrm{ClC}-2$ expression that was observed must also be considered in the context of factors that could modify the functional activity of the channel. CIC-2 function may be regulated by different second-messenger systems in specific neuronal populations. The amount of mRNA may not directly reflect the amount of protein in the cells. Furthermore, the subcellular distribution of $\mathrm{ClC}-2$ will determine the functional effects seen in individual neurons. Specifically, a non-uniform distribution could establish a $\mathrm{Cl}^{-}$gradient within neurons if $\mathrm{ClC}-2$ is present on neuronal processes and soma in different amounts. Therefore, understanding both the regulation and pattern of cell distribution will be required to fully understand the functional significance of the differential expression of $\mathrm{ClC}-2$ in regulating neuronal physiology.

\section{References}

Ben-Ari Y, Cherubini E, Corradetti R, Gaiarsa JL (1989) Giant synaptic potentials in immature rat CA3 hippocampal neurons. J Physiol (Lond) 416:303-325.

Blatz AL (1991) Properties of single fast chloride channels from rat cerebral cortex neurons. J Physiol (Lond) 441:1-21.

Buhl EH, Halsay K, Somogyi P (1994) Diverse sources of hippocampal unitary inhibitory postsynaptic potentials and the number of synaptic release sites. Nature 368:823-828.

Buzsaki G, Horvath Z, Urioste R, Hetke J, Wise K (1992) High-frequency network oscillation in the hippocampus. Science 256:10251027.

Chesnoy-Marchais D (1983) Characterization of a chloride conduc tance activated by hyperpolarization in aplysia neurones. J Physiol (Lond) 342:277-308.

Fizman ML, Novotny EA, Lange GD, Barker JL (1990) Embryonic and early postnatal hippocampal cells respond to nanomolar concentrations of muscimol. Dev Brain Res 53:186-193.

Frohman MA (1994) Cloning PCR products. In: The polymerase chain reaction (Mullis KB, Ferre F, Gibbs RA, eds), pp 14-37. Boston: Birkhauser.

Grunder S, Thiemann A, Pusch M, Jentsch TJ (1992) Regions involved in the opening of $\mathrm{ClC}$-2-chloride channel by voltage and cell volume. Nature 360:759-762.

Javaheri S (1991) Role of $\mathrm{NaCl}$ co-transport in cerebrospinal fluid production: effects of loop diuretics. J Appl Physiol 71:795-800.

Jentsch TJ, Steinmeyer K, Schwarz G (1990) Primary structure of Torpedo marmorata chloride channel isolated by expression cloning in Xenopus oocytes. Nature 348:510-514.

Kawashi M, Uchida S, Monkawa T, Miyawaki A, Mikoshiba K, Marumo F, Sasaki S (1994) Cloning and expression of a protein kinase C-regulated chloride channel abundantly expressed in rat brain neuronal cells. Neuron 12:597-604.

Madison DV, Malenka RC, Nicoll RA (1986) Phorbol esters block a voltage sensitive chloride current in hippocampal pyrannidal cells. Nature 321:695-697.

McIntire SL, Jorgenson E, Kaplan J, Horvitz H (1993) The GABAergic nervous system of Caenorhabditis elegans. Nature 364:337-341.

Michelson HB, Wong RKS (1991) Excitatory synaptic responses mediated by $\mathrm{GABA}_{\mathrm{A}}$ receptors in the hippocampus. Science 253:14201423.

Misgeld U, Deisz RA, Dodt HU, Lux HD (1986) The role of chloride transport in postsynaptic inhibition of hippocampal neurons. Science 232:1413-1415.

Parker I, Miledi R (1988) A calcium independent chloride current activated by hyperpolarization in Xenopus oocytes. Proc R Soc Lond [Biol] 233:191-199.

Qian N, Sejnowski T (1990) When is an inhibitory synapse effective? Proc Natl Acad Sci USA 87:8145-8149.

Ribak CE, Vaughn JE, Saito K (1978) Immunocytochemical localization of glutamic acid decarboxylase in neuronal somata following colchicine inhlibition of axonal transport. Brain Res 140:315-332.

Sambrook J, Fritich EF, Maniatis T (1989) Molecular cloning: a laboratory manual. Cold Spring Harbor, NY: Cold Spring Harbor Laboratory.

Seress L, Ribak CE (1983) GABAergic cells in the dentate gyrus appear to be local circuit and projection neurons. Exp Brain Res 50: 173-182.

Smith RL, Escudero JM, Wilcox CL (1994) Regulation of the herpes simplex virus latency-associated transcripts during establishment of latency in sensory neurons in vitro. Virology 201:49-61.

Staley KJ (1992) Enhancement of the excitatory actions of GABA by barbituates and benzodiazapines. Neurosci Lett 146:105-107.

Staley KJ (1994) The role of an inwardly rectifying chloride conductance in postsynaptic inhibition. J Neurophysiol 72:273-284.

Staley KJ, Otis T, Mody I (1992) Membrane properties of dentate gyrus granule cells comparison of sharp microelectrode and whole-cell recordings. J Neurophysiol 67:1346-1358.

Steinmeyer K, Ortland C, Jentsch TJ (1991) Primary structure and functional expression of a developmentally regulated skeletal muscle chloride channel. Nature 354:301-304

Thiemann A, Grunder S, Pusch M, Jentsch TJ (1992) A chloride channel widely expressed in epithelial and non-epithelial cells. Nature 356:57-60.

Thompson SM, Gawhiler BH (1989) Activity-dependent disinhibition. II. Effects of extracellular potassium, furosemide and membrane potential on $E_{\mathrm{C}^{-}}{ }^{-}$in hippocampal CA3 neurons. J Neurophysiol 61:512523.

Uchida S, Sasaki S, Furukawa T, Hiraoka M, Imai T, Hirata Y, Marumo $F$ (1993) Molecular cloning of a chloride channel that is regulated and expressed predominantly in kidney medulla. J Biol Chem 268: 3821-3824.

Wong RKS, Watkins DJ (1982) Cellular factors influencing GABA response in hippocampal pyramidal cells. J Neurophysiol 48:938951

Xie X, Smart TG (1991) ^ physiological role for endogenous zinc in rat hippocampal synaptic neurotransmission. Nature 349:521-524.

Xie X, Smart TG (1993) Properties of GABA-mediated synaptic potentials induced by zinc in adult rat hippocampal neurons. J Physiol (Lond) 460:503-523.

Zhang JS, Jackson MB (1993) GABA-activated chloride channels in secretory nerve endings. Science 259:531-534. 